\title{
Hevea Culture - A Potential Economic Growth for the State of Rio de Janeiro
}

\author{
Harrison Lourenço Corrêa ${ }^{1, *}$, Rachel Alves ${ }^{1}$, Marco Gaya de Figueiredo ${ }^{2}$, Cristina Russi G. Furtado ${ }^{3}$ \\ ${ }^{1}$ Institute of Technology, Department of Chemical Engineering, Universidade Federal Rural do Rio de Janeiro, Seropédica, Brazil \\ ${ }^{2}$ Chemical Institute, Department of Operations and Industrial Projects, Universidade do Estado do Rio de Janeiro, Rio de Janeiro, Brazil \\ ${ }^{3}$ Chemical Institute, Department of Chemical Processes, Universidade do Estado do Rio de Janeiro, Rio de Janeiro, Brazil
}

\begin{abstract}
In a world where we discuss sustainability as the central axis of development, it is essential that a country like Brazil takes responsibility to adopt new technologies that contribute to the this sector. Taking advantage of the need that the country has to ally economic growth with social inclusion and maintenance of natural resources, the adoption of technologies that reduce the emission of greenhouse gases is promising. In this sense, stimulate the hevea culture appears to be an important allied in the fight to the concentration of $\mathrm{CO}_{2}$ in the atmosphere, since it allows its uptake by the trees. The retaken of this vegetal exploitation in Brazil (specially by the State of Rio de Janeiro), taking the social inclusion as a guiding policy, can be crucial to the fight against poverty and unemployment. This exploitation will allow to create conditions for small farmers to participate in the production chain of natural rubber, raw material extracted from rubber trees.
\end{abstract}

Keywords Hevea culture, Social inclusion, Rio de Janeiro

\section{Introduction}

The increasing demand for polymeric products, mainly petrochemical origin, associated with the search for industrial production processes within the context of sustainable development, makes use of plant resources for the production of rubber a technological alternative and environmentally interesting [1].

In this scenario, the cultivation of rubber trees (Hevea) appears promising [2-4]. As evidence of this, the International Rubber Study Group forecast an increase in world production of natural rubber (NR) in $7.8 \%$ for the year, totaling 11.8 million tons. This volume should be, even according to the group, the expansion of areas intended for natural rubber during the mid-2000s [5]. The indicative of expansion for the year 2012 are still reinforced by Goldman Sachs Group Inc., which designs for this year the highest production since 2004.

Nowadays, the State of Rio de Janeiro has the support of the Pesagro-RJ (Rio de Janeiro Department of Agriculture) to promote rubber cultivation in the region, helping to ensure the technical and human resources for the sector, specially to the small farmers interested in the NR exploitation. Currently, according to data obtained by the same department, the State has a planted area of 600 hectares

* Corresponding author:

harrisoncorrea@ufrrj.br (Harrison Lourenço Corrêa)

Published online at http://journal.sapub.org/re

Copyright @ 2016 Scientific \& Academic Publishing. All Rights Reserved
(ITEB, 2014). Given the domestic demand for NR and the recent attempt to commercially exploit the hevea in the state, this work introduces a preliminary analysis of economic data on trade in NR in Brazil, especially those that refer to the State of Rio de Janeiro.

\section{Material and Methods}

To perform this study, we consulted the databases Aliceweb 2.0 and the Radar Comercial, both from the Ministry of Development, Industry and Foreign Trade of Brazil.

The query was defined for the period 2008 to 2015 . The Import and export data of natural rubber latex (query parameter NCM 40011000) were analyzed at the level of Brazil and the unity of the Federation (Rio de Janeiro).

It was set as a parameter search only economic bloc "Asia", which are already recognized the NR suppliers to Brazil. The data supplied in sheets, were converted to graphs for further analysis.

\section{Results and Discussion}

In the period 2008 to 2015, were imported almost 150,000 tonnes of natural rubber latex. In contrast, Brazil exported 8.5 tons so only. The volume of raw material exports, less than $0.1 \%$ of total imports, clearly demonstrates the dependence of the internal market to latex produced in other countries. Figure 1 shows the amount (t) 
of NR latex marketed within 4 years.

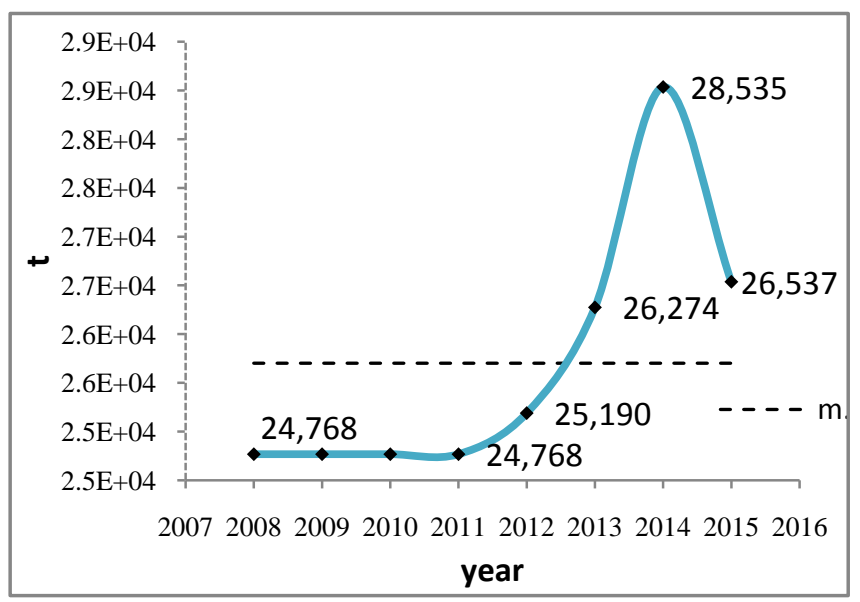

Figure 1. Quantity in tonnes of NR latex imported by Brazil in the period 2008 to 2015

The average annual import was over 25,000 tons. The maximum volume of imports occurred in 2014 (9.9\% above average). The year 2011 recorded the lowest volume of imports, with value $3.8 \%$ below the average of the period.

The main exporters of NR in Brazil are, according to the Ministry, Indonesia and Thailand, which together contributed to a turnover of more than 140 million dollars just in negotiations related materials (including latex and coagulated). In 2010, Brazil was the fourth largest buyer of NR latex in Thailand, contributing to the acquisition of $1.5 \%$ of the total produced by this country, as shown in Figure 2.

The growth in the period 2008 to 2010 in total participation was nearly $19 \%$.
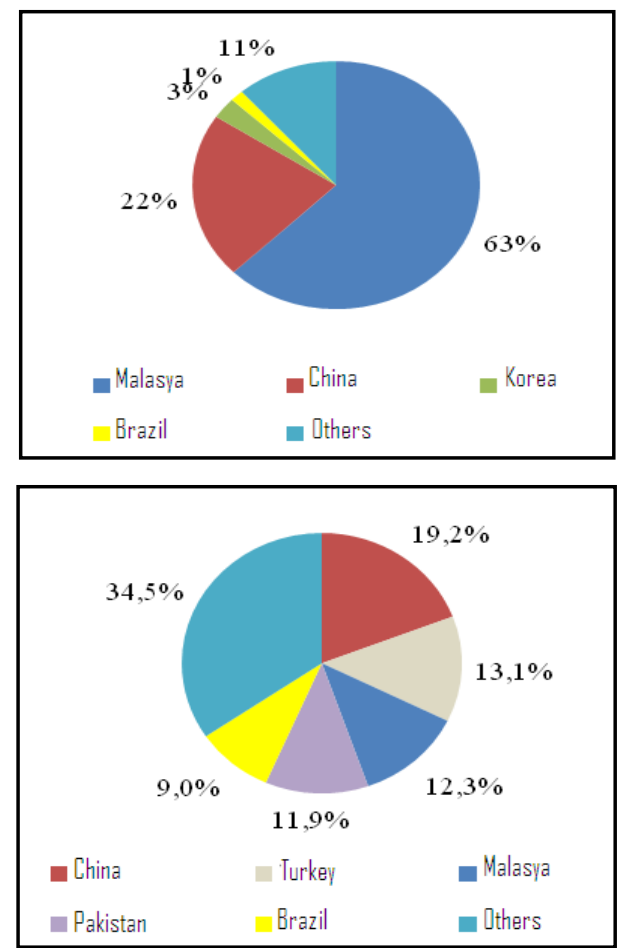

Figure 2. Major buyers of Thailand NR latex (a) and Indonesia (b) in the year 2010 (Adapted from: MDIC, 2012)
Figure 2 (b) shows that Brazil's participation in the Indonesian market for NR latex was more expressive.

In 2010 the country bought about $9 \%$ of total raw material produced in Indonesia, representing a negotiated amount of almost \$ 3 million [6]. Indonesia in the period 2008 to 2010 increased its sales to Brazil in more than $733 \%$, still according to the Ministry. Figure 3 shows the total imported by federal unit, considering the economic bloc in Asia (excluding Middle East).

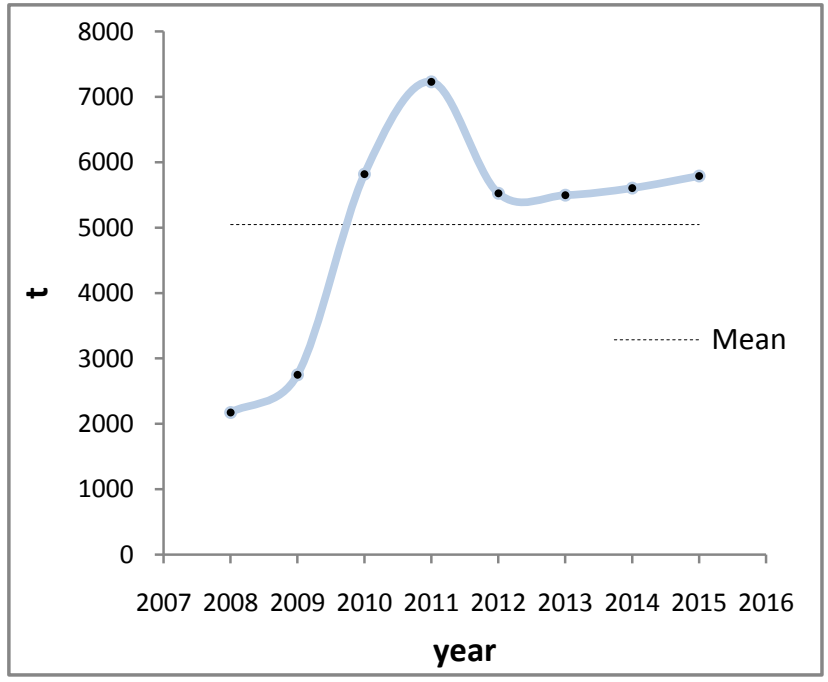

Figure 3. Quantity in tonnes of NR latex imported by the State of Rio de Janeiro (Adapted from: MDIC, 2016)

Since 2008 there is an increasing trend in imports of NR latex. The years 2010 and 2011 represented major increases in imports, reaching values of 29 and $61 \%$ above the average for the period. Taking Thailand as the main supplier, selling to the market of Rio de Janeiro increased over the years, reaching a maximum value in 2010, according to Figure 4.

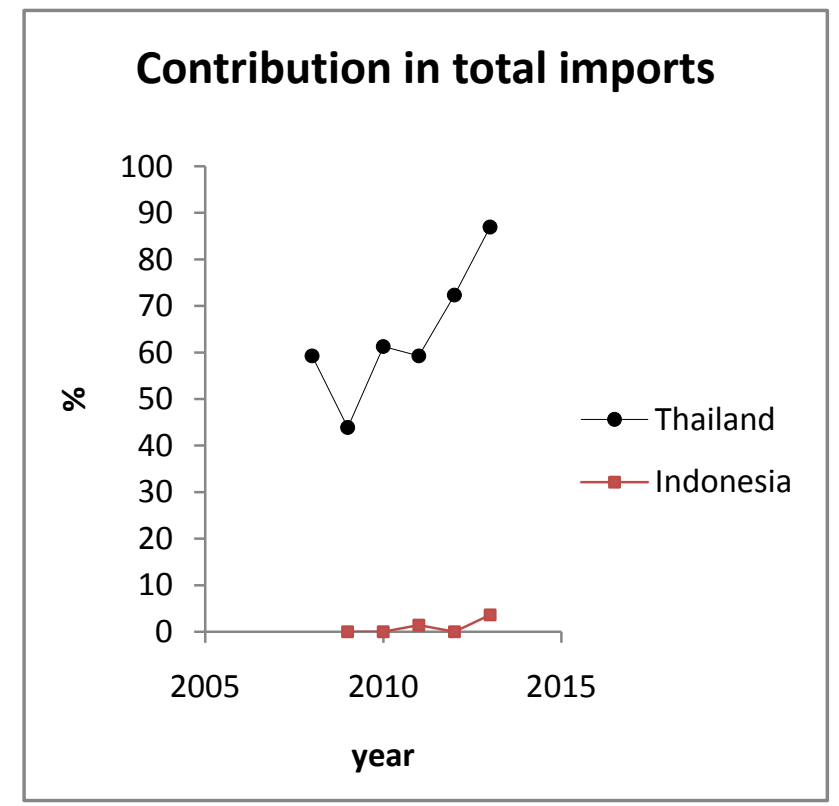

Figure 4. Thailand's participation in the market for NR latex provided to the State of Rio de Janeiro (Adapted from: MDIC, 2014) 


\section{Conclusions}

Given the current scenario in which Brazil has stood out in the world economy, the demand for NR latex to meet certain production sectors becomes evident. Taking advantage of the fact that a major tire industry is located in its territory, the State of Rio de Janeiro is a strategic buyer of raw material in question. Since 2008, there was an upward trend in imports of NR latex by the State. Thailand and Indonesia are the main suppliers. Coupled with the possibility of trading carbon credits, the culture of hevea has been highlighted in major public and private institutions, which develop projects for the implementation of culture in the State of Rio de Janeiro.

\section{ACKNOWLEDGEMENTS}

We are grateful to Universidade Federal Rural do Rio de Janeiro for the financial support.

\section{REFERENCES}

[1] Corrêa, H., Furtado, C., Sousa, Ana. Calculation of the flow activation energy of natural rubber látex (NRL). In: HAMILTON, Janet (Ed.). Natural rubber - properties, behavior and applications. Nova Publishers, p.33, 2016.
[2] A., Oliveira, C. do Carmo, R. da Cruz. A cultura da seringueira no estado do Rio de Janeiro - perspectivas e recomendações técnicas. Empresa de Pesquisa Agropecuária do Estado do Rio de Janeiro (2009).

[3] R., Moreno, P. Gonçalves, E. Vaidergorin, L. Mattoso. Avaliação das propriedades da borracha natural de clones da região de Matão -SP. Trabalho apresentado no I Ciclo de Palestras sobre a Heveicultura Paulista, Barretos-SP, 10 a 11 de Novembro (1998).

[4] Moreno, R., Gonçalves, P., Mattoso, L. Desempenho da borracha natural crua de novos clones de seringueira (hevea spp.) da série IAC para recomendação ao plantio no Estado de São Paulo: I - as propriedades tecnológicas P0, PRI (\%) e V R. Circular Técnica, 27, Ministério da Agricultura, Pecuária e Abastecimento (2005) 1-5.

[5] IRGS. International Rubber Study Group. Available in < http://rubberasia.com/v2/index.php?option=com_content\&vi $\mathrm{ew}=$ section $\&$ layout $=$ blog $\& \mathrm{id}=8 \&$ Itemid $=15>$. Acessed in 10th february 2012.

[6] Ministry of Development, Industry and Foreign Trade from Brazil, 2012. 